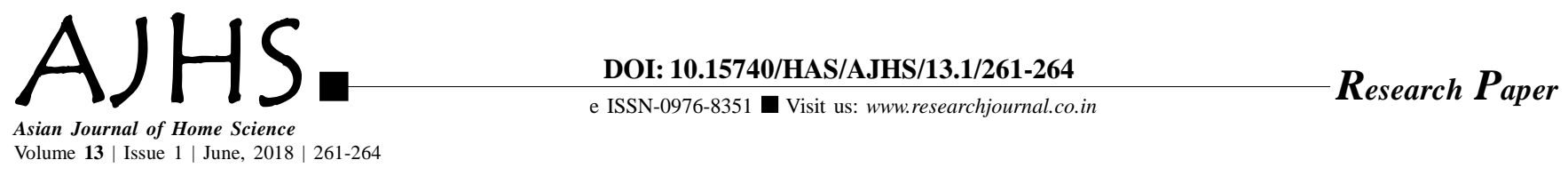

\title{
Physical and mechanical properties of cotton/nettle union fabrics
}

Neha Garg, Harinder Kaur Saggu and Kanwaljit Kaur Brar

Received: 24.11.2017; Revised: 09.04.2018; Accepted: 30.04.2018

See end of the paper for authors' affiliations Neha Garg

Department of Apparel and Textile Science, College of Home Science, Punjab Agricultural University, Ludhiana (Punjab) India
ABSTRACT : The naturalism trend has established sectors in the textile and fashion industry also. Nettle fibres will take a major role in the emerging "green" economy based on energy efficiency, industrial processes that reduce carbon emissions and recyclable materials that minimize waste. Natural fibres are a kind of renewable resources. These are also carbon neutral; they absorb the equal amount of carbon dioxide they produce. These fibres are completely renewable, environmental friendly and bio-degradability. Also, this paper focused on different properties of cotton/nettle union fabrics. The cotton/nettle union fabrics were constructed to study the properties of fabric. To construct cotton/nettle union fabric, the cotton yarn was used as warp with nettle weft. In the study, the fabrics were prepared with three different weaves (plain, twill and basket weave). Union fabric was much cheaper in cost compared to pure nettle fabric. Those woven fabrics were tested for physical and mechanical properties. Further, data were evaluated to find out the influence of physical and mechanical properties.

KEY WORDS: Cotton/nettle union fabric, Physical, Mechanical properties

- HOW TO CITE THIS PAPER : Garg, Neha, Saggu, Harinder Kaur and Brar, Kanwaljit Kaur (2018). Physical and mechanical properties of cotton/nettle union fabrics. Asian J. Home Sci., 13 (1) : 261-264, DOI: 10.15740/HAS/AJHS/13.1/261-264. Copyright@ 2018: Hind Agri-Horticultural Society. 